American Journal of Applied Sciences 7 (7): 937-942, 2010

ISSN 1546-9239

(C) 2010 Science Publications

\title{
Integration of Comfort into a Driver's Car Seat Design Using Image Analysis
}

\author{
Darliana Mohamad, Baba Md Deros, Dzuraidah Abdul Wahab, \\ Dian Darina Indah Daruis and Ahmad Rasdan Ismail \\ Department of Mechanical and Materials Engineering, \\ Faculty of Engineering and Built Environment, \\ University Kebangsaan Malaysia, Bangi Selangor, 43600 Malaysia
}

\begin{abstract}
Problem statement: The purposes of this study are twofold: First, to recommend a range of angles for driving posture comfort from measurement of participants and second, to investigate the relationships between drivers' anthropometric characteristics, comfortable postural angles and seat adjustment. Approach: Forty five participants were involved in the study. Both anthropometric data and postural angles were measured and recorded by using the photographic technique and analyzed further using software. During the study, each participant was required to sit on the driver's seat in his or her preferred comfortable driving postures. Images of the participant's driving posture were taken after $5 \mathrm{~min}$ he or she has been in the driving position to allow him/her to adapt with the seat environment and fabrics. The seat adjustment data were measured manually after the seat is adjusted for comfort by the participant. Prior to that, 10 anthropometric data of each participant was measured and recorded. Data on comfortable driving postural angles, anthropometry and seat adjustment were analyzed statistically with Pearson correlation using the SPSS software. Results: From the study, a range of angles are proposed based on the participant's perception on comfort. The ranges of comfortable angles for Malaysian citizen proposed shows significant different between Caucasian and Korean populations. The relationships between the comfortable postural angles, anthropometric data and seat adjustment were analyzed and discussed with several outcome shows that taller participants preferred a driving posture with their arms outstretched in order to achieve comfort, participants with bigger body dimension have a tendency to sit farther back from the steering wheels and smaller participants prefer to sit closer to the steering wheels with a slightly greater trunk thigh angle. Conclusion: The result obtained and discussed in this study can be applied in the driver's car seat design and construction to ensure comfort and safety.
\end{abstract}

Key words: Driving angles, anthropometric, comfort, posture

\section{INTRODUCTION}

Today's global competition has prompted many automotive manufacturers to design their products based on consumer's preference and satisfaction. In a car seat design and development, posture of car drivers among others is a critical factor that had to be considered closely and effectively. A car driver controls the vehicle and his/her comfort and safety is important to avoid any road injury or unfortunate accident.

A comfortable and safe driver's seat plays a very important role in car design and fabrication. As mentioned by Na et al. (2005), drivers' comfort was as important as the functional and aesthetic design of automobiles since consumers are more and more concerned about safety and comfortable driving.
Ergonomics is one of the important factors to consider in designing a seat. Ergonomics is basically the applications of science in human life for comfort and safety. One of the most important contributions that ergonomics can provide to the automobile design process is information of the physical size of driver and his/her preferred postures (Porter and Gyi, 1998).

This study is focusing on the comfort of the car drivers' posture. As gathered from previous literature, fatigue is always associated with long duration of driving. Fatigue resulting from long-term driving can affect driver performance and are classified into physical and mental fatigue. On the other hand, physical fatigue is mainly caused by driving posture (Hirao et al., 2006). An experiment conducted by Costanzo et al. (1999) detected the different levels of

Corresponding Author: Darliana Mohamad, Department of Mechanical and Materials Engineering, Faculty of Engineering and Built Environment, University Kebangsaan Malaysia, Bangi Selangor, 43600 Malaysia 
muscular fatigue between correct and incorrect postures. A field measuring devices which was introduced by Hermanns et al. (2008) also showed that awkward postures and high vibration exposure while in driving position might resulted in high risk condition for musculoskeletal disorders.

There have been many past research and experiments conducted in driver's car posture ( $\mathrm{Na}$ et al., 2005; Hirao et al., 2006; Hermanns et al., 2008; Falou et al., 2003; Park et al., 2000; Andreoni et al., 2002; Kyung and Nussbaum, 2008; Reed et al., 2000; Sun et al., 2006) but none was conducted for the Malaysian population. So, this study is aiming to publish comfortable and safe driving postures as preferred by Malaysian car drivers.

In addition, it is interesting to investigate the relationship between anthropometric data of the subjects and the driver's seat adjustment with the comfortable postural angle measured. Studies on comfortable postural angle have been carried out by several researches such as Park et al. (2000); Porter and Gyi (1998); Grandjean (1980) and Rebiffe (1969), however the studies did not include all angles of the human driving posture. Meanwhile, in this study all possible related angles with respect to comfort for drivers' postures will be determined.

The aim of this study are twofold: first, to recommend a range of angles for driving posture comfort from measurement of samples and second, is to investigate the relationships between car drivers' anthropometric characteristics, comfortable postural angles and seat adjustment. The comfortable postural driving angles and the relationships between the comfortable driving postures, anthropometric data and seat adjustment presented in this study would be able to assist designer and engineers in car seat design and construction to ensure comfort and safety of the drivers.

\section{MATERIALS AND METHODS}

The participants and parameters of study procedure for data measurement process and the statistical analysis are described in detailed.

Participants: The numbers of participants involved in this experiment was 45 Malaysian citizens which comprise of 19 females and 26 males. The participants' age ranged from 20-30 years old. Minimum driving experience is one year to ensure the drivers have adequate experience in driving. As a token, the participants were given some incentives for their contribution.

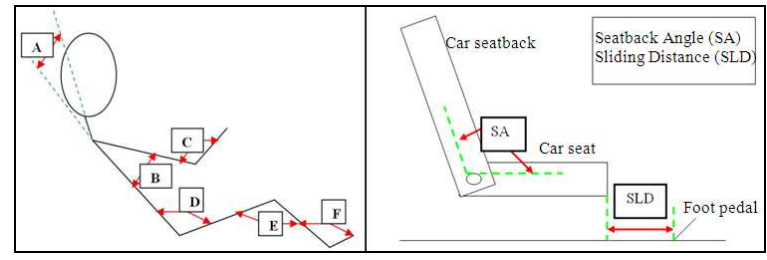

Fig. 1: Driving postural angles and seat adjustments

Parameters: The measured dimensions for this study were chosen based on literature studies and direct relation with the parameter needed in the experiment. Ten anthropometric data were measured from each participant: stature, sitting height, hip height, knee height, shoulder to elbow length, sitting shoulder height, sitting waist height, hip breadth, elbow to grip length and shoulder breadth. These ten anthropometric data were chosen because they directly related to the driving posture. All anthropometric data collected is based on MS ISO 7250 (Malaysian Standard, 2003). For the angle measurement, six angles were chosen, including the neck angle (A), shoulder angle (B), elbow angle (C), trunk-thigh angle (D), knee angle (E) and foot angle $(\mathrm{F})$ as shown in Fig. 1. Two parameters for the seat adjustment were measured; they are the sliding distance and the seatback angle (Fig. 1). These seat parameters were used to investigate the correlation between the anthropometric data and comfortable driving postural angles.

Driving postural angles were taken from three different cars, Compact A, Medium Sedan B and Premium Sedan C. The cars chosen are from compact and entry midsize segment cars. These cars represent the highest, average and the lowest ranks of cars used in Malaysia according to the survey by JD Power and Associates (2008).

The selected cars shared equal features on the drivers' seat such as manual adjustment of the seat track and the seat back, no armrest and standard fabric cover. It is important to ensure the shared features so as to minimize the aesthetic effects on the participants' subjective responses (Kyung and Nussbaum, 2008).

Procedure: Prior to the data measurement process, the objectives and procedures of the study were explained in detail and participants were required to fill in their personal information in a form given to them. The data includes personal information such as age, gender, race, state of origin, date of birth and occupation. The measured anthropometrics dimensions were recorded in the same form. Before the postural angle measurement process was carried out, each participant anthropometric data was photographed and recorded. 
Participants are then required to sit on the driver's seat in their comfortable driving postures. Four sticker markers were positioned on the anatomical landmarks of the subject. Images taken for anthropometric measurement and postural angles are recorded for further analysis. On average, it took $10 \mathrm{~min}$ to measure all the ten anthropometric dimensions and six postural angles. The same process for postural angles measurement was repeated twice for each subject on two different days at about the same time so that the data can be averaged for repeatability and reliability purposes.

Both anthropometric data and postural angles measurement were recorded and measured using photographic technique. Images of participants were taken and analyzed using software as mentioned in next paragraph. The photography technique was chosen to reduce time and hassle in the measurement process.

For anthropometric data, the measurement process comprise of the hardware setup for the background board plane and web camera position and usability of measurement software called Vision Assisted Anthropometric Measurement System (VAAMS).

As for driving postural angles, the Seat Postural Angles Measurements Systems (SPAMS) will be used. The side view of subject comfortable driving posture was photographed and recorded by the software. Later, this software will generate the required angles. This software was developed in-house specifically for this study.

The manual measurement method was used to gather the seat adjustment parameters data. The measurement tools used consist of the basic L-shape ruler and a tape measurement. Data were recorded manually into the form sheet provided. These seat adjustment parameters were taken after the seat had been adjusted by the participant according to their preference on driving comfort.
Statistical analysis: Data management and analysis was performed using SPSS for Windows (version 15.0). Data on postural angle, anthropometry data and seat adjustment are analyzed statistically in order to achieve the objectives of the study. The relationship between the comfortable postural angles, anthropometric characteristics and seat adjustment were analyzed using Pearson correlation. The correlation will indicate the level of influence for every anthropometric data measured and the postural angles based on rule of thumb interpretation by Hinkle et al. (1998).

\section{RESULTS}

The result from the study conducted is presented here.

Postural angles: A descriptive statistical analysis was used to obtain the comfortable postural angles as presented in Table 1. Table 1 also shows the comparison of recommended postural data from earlier studies conducted in other countries. As seen from Table 1, most past researchers only measured four or five angles. For the purpose of this study, the neck angle is also measured as carried out by Massaccesi et al. (2003) who showed that there are high loading at the neck area for drivers which means that drivers have a high incidence of spinal disorders in terms of back and neck pain.

Correlation results: As stated earlier, one of the main objectives of this study is to discuss the relationship between the comfortable postural angles, anthropometric data and seat adjustment. In order to obtain this relationship, a Pearson correlation analysis is conducted. Table 2 illustrates the results of correlation using Pearson analysis.

Table 1: Comfortable driving postural angle (in degree) and comparison between past researchers

\begin{tabular}{|c|c|c|c|c|c|c|c|}
\hline Classification & $\begin{array}{l}\text { Observed postures } \\
(\mathrm{n}=45) \text { mean }(\mathrm{SD}) \\
\text { range }\end{array}$ & $\begin{array}{l}\text { Male }(\mathrm{n}=26) \\
\text { mean }(\mathrm{SD}) \\
\text { range }\end{array}$ & $\begin{array}{l}\text { Female }(\mathrm{n}=19) \\
\text { mean }(\mathrm{SD}) \\
\text { range }\end{array}$ & $\begin{array}{l}\text { Park et al. } \\
(2000)\end{array}$ & $\begin{array}{l}\text { Porter and Gyi } \\
\text { (1998) }\end{array}$ & $\begin{array}{l}\text { Grandjean } \\
(1980)\end{array}$ & $\begin{array}{l}\text { Rebiffe } \\
(1969)\end{array}$ \\
\hline \multirow[t]{2}{*}{ Neck angle } & $35.47(6.25)$ & $35.31(6.38)$ & $35.70(6.11)$ & & & & \\
\hline & $22-48$ & $24-48$ & $22-48$ & NA & NA & NA & NA \\
\hline \multirow[t]{2}{*}{ Elbow angle } & $134.02(17.76)$ & 138.97 (17.18) & $127.25(16.36)$ & $113.0(14.01)$ & & & \\
\hline & $100-188$ & $100-188$ & $101-167$ & $86-144$ & $86-164$ & NA & $80-120$ \\
\hline \multirow[t]{2}{*}{ Shoulder angles } & $36.18(7.92)$ & $37.18(7.54)$ & $34.81(8.29)$ & $19.5(6.38)$ & & & \\
\hline & $16-61$ & $16-51$ & $21-61$ & $7-37$ & NA & NA & NA \\
\hline \multirow[t]{2}{*}{ Trunk-thigh angle } & $110.30(4.98)$ & $109.62(4.90)$ & $111.23(4.98)$ & $117.4(7.71)$ & & & \\
\hline & $96-123$ & $96-119$ & $102-123$ & $103-131$ & $90-115$ & $100-120$ & $95-120$ \\
\hline \multirow[t]{2}{*}{ Knee angle } & $119.76(7.97)$ & $119.04(7.23)$ & $120.74(8.85)$ & $133.7(8.53)$ & & & \\
\hline & $102-143$ & $102-137$ & $102-143$ & $120-152$ & $99-138$ & $110-130$ & $95-135$ \\
\hline \multirow[t]{2}{*}{ Foot angle } & $90.18(8.05)$ & $90.24(7.45)$ & $90.09(8.88)$ & $100.8(8.61)$ & & & \\
\hline & $69-116$ & $73-108$ & $69-116$ & $82-124$ & $80-113$ & $90-110$ & $90-110$ \\
\hline
\end{tabular}


Am. J. Applied Sci., 7 (7): 937-942, 2010

Table 2: Comfortable driving postural angle (in degree) and comparison between past researchers

\begin{tabular}{|c|c|c|c|c|c|c|c|c|}
\hline Classification & Neck angle & Elbow angle & Shoulder angle & Trunk thigh angle & Knee angle & Foot angle & Sliding distance & Seatback angle \\
\hline Stature & -0.131 & $0.451(* *)$ & $0.320(*)$ & 0.019 & 0.034 & -0.021 & $0.506(* *)$ & 0.227 \\
\hline Hip height & -0.059 & 0.169 & 0.011 & $-0.350(*)$ & -0.282 & -0.173 & $0.556\left(^{* *}\right)$ & 0.131 \\
\hline Knee height & 0.095 & 0.088 & -0.059 & $-0.314(*)$ & -0.291 & -0.197 & $0.465(* *)$ & 0.004 \\
\hline Hip breadth & -0.081 & $0.426(* *)$ & 0.255 & 0.088 & 0.121 & 0.020 & $0.501(* *)$ & 0.125 \\
\hline Shoulder breadth & -0.142 & 0.215 & 0.045 & $-0.311(*)$ & -0.207 & -0.164 & $0.649(* *)$ & -0.058 \\
\hline Sitting height & -0.103 & $\left.0.319{ }^{*}\right)$ & 0.097 & -0.240 & -0.161 & -0.211 & $0.627(* *)$ & 0.102 \\
\hline Sitting shoulder height & -0.089 & 0.143 & -0.012 & -0.284 & -0.081 & -0.094 & $0.503(* *)$ & -0.093 \\
\hline Sitting waist height & 0.054 & 0.178 & 0.039 & 0.121 & 0.133 & 0.083 & 0.280 & -0.105 \\
\hline Elbow to grip length & 0.021 & 0.085 & -0.066 & $-0.441(* *)$ & -0.242 & 0.034 & $0.587(* *)$ & -0.075 \\
\hline Shoulder to elbow length & 0.128 & -0.031 & -0.250 & $-0.383(* *)$ & $-0.348(*)$ & -0.145 & $0.422(* *)$ & 0.016 \\
\hline Neck angle & 1.000 & 0.116 & 0.001 & 0.141 & $-0.339(*)$ & -0.137 & -0.250 & 0.240 \\
\hline Elbow angle & 0.116 & 1.000 & $0.867(* *)$ & $0.588(* *)$ & 0.234 & 0.073 & $0.441(* *)$ & 0.422 (**) \\
\hline Shoulder angle & 0.001 & $0.867(* *)$ & 1.000 & $0.488(* *)$ & 0.283 & 0.032 & $0.328(*)$ & $0.358(*)$ \\
\hline Trunk thigh angle & 0.141 & $0.588(* *)$ & $0.488(* *)$ & 1.000 & $0.532(* *)$ & 0.245 & -0.151 & $0.343(*)$ \\
\hline Knee angle & $-0.339(*)$ & 0.234 & 0.283 & $0.532(* *)$ & 1.000 & $0.555(* *)$ & $0.308(*)$ & -0.055 \\
\hline Foot angle & -0.137 & 0.073 & 0.032 & 0.245 & $0.555(* *)$ & 1.000 & 0.218 & -0.111 \\
\hline Sliding distance & -0.250 & $0.441(* *)$ & $0.328(*)$ & -0.151 & $0.308(*)$ & 0.218 & 1.000 & -0.074 \\
\hline Seatback angle & 0.240 & 0.422 (**) & $0.358(*)$ & $0.343(*)$ & -0.055 & -0.111 & -0.074 & 1.000 \\
\hline
\end{tabular}

*: Correlation is significant at the 0.05 level (2-tailed); **: Correlation is significant at the 0.01 level (2-tailed)

\section{DISCUSSION}

It is apparent from the results in Table 1 that the elbow angle was significantly larger than the ranges found in other studies. Differences are also observed between Malaysian and Korean population from Park et al. (2000) as shown in Fig. 2 mean comparisons graph. From the graph, it can be seen the differences in angles proposed even though both countries are from the same region.

The data on postural angles in Table 1 also show that there are differences of range angles value between Malaysian and Caucasians data which are from Porter and Gyi (1998); Grandjean (1980) and Rebiffe (1969). But, the differences cannot be proven statistically due to limited of information and resource. However, this observed difference is in line with the result from past research by Park et al. (2000). The differences between other populations showed that it is necessary for the Malaysia population to propose its own recommended driving posture in order to ensure driver's safety and comfort.

From Pearson correlation in Table 2, the Null hypothesis $\left(\mathrm{H}_{0}\right)$ indicates that there is no correlation while the alternate hypothesis $\left(\mathrm{H}_{1}\right)$ indicates that there is a correlation relationship. The $\mathrm{H}_{0}$ will be rejected if the p-value is below the significant level 0.05 and 0.01 . The correlation coefficient results are interpreted based on the rule of thumb by Hinkle et al. (1998).

It can be seen from the data in Table 2 that several relationships need to be discussed among the comfortable postural angles, anthropometric data and seat adjustment. There is a very high positive correlation between the elbow angle and shoulder angle (correlation coefficient $0.867, \mathrm{p}<0.01$ ). Interestingly, this correlation results is in line with the study by Park et al. (2000) which shows the same relationship between this two parameters. In addition, a positive moderate correlation was found between the stature and elbow angle (coefficient correlation 0.451, p<0.01).

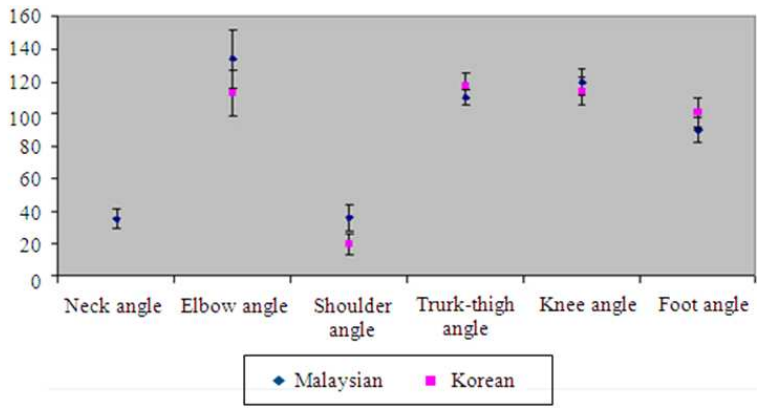

Fig. 2: Mean comparisons of postural angles between Malaysian and Korean

This shows that taller participants preferred a driving posture with their arms outstretched in order to achieve comfort. This statement is supported by the positive moderate correlation found between the trunk thigh angle and elbow angle (coefficient correlation, 0.588, $\mathrm{p}<0.01$ ), shoulder angle (coefficient correlation, 0.488, $\mathrm{p}<0.01$ ) and knee angles (coefficient correlation, 0.532, $\mathrm{p}<0.01)$.

There are also several positive moderate correlation between the sliding distance and several anthropometric data measured that were the stature (coefficient correlation 0.506, $\mathrm{p}<0.01$ ), hip height (coefficient correlation 0.556, $\mathrm{p}<0.01$ ), knee height (coefficient correlation $0.465, \mathrm{p}<0.01$ ), hip breadth (coefficient correlation, 0.501, $\mathrm{p}<0.01$ ), shoulder breadth (coefficient correlation, 0.649, $\mathrm{p}<0.01$ ), sitting height (coefficient correlation, 0.627, $\mathrm{p}<0.01$ ), sitting shoulder height (coefficient correlation, 0.503, p<0.01) and elbow to grip length (coefficient correlation 0.587, $\mathrm{p}<0.01$ ). This explains that the participants with bigger body dimension have a tendency to sit further back from the steering wheels. 
Conversely, it can be concluded that smaller participants prefer to sit closer to the steering wheels with a slightly greater trunk thigh angle. This rationalization was confirmed by the negative low correlation found between the trunk- thigh angles and hip height (coefficient correlation, $-0.35, \mathrm{p}<0.01$ ), knee height (coefficient correlation, $-0.314, \quad \mathrm{p}<0.01$ ), shoulder breadth (coefficient correlation, -0.311, $\mathrm{p}<0.01$ ), elbow to grip length (coefficient correlation, $0.441, \quad \mathrm{p}<0.01$ ) and shoulder to elbow length (coefficient correlation, $-0.383, \mathrm{p}<0.01$ ). This result is similar to the study by Park et al. (2000) that resulted in a negative correlation between the trunk-thigh angle and lower limb lengths, calf to lateral condyle and lateral condyle to greater hip and upper limb length, lateral epicondyle to ulnar styloid.

\section{CONCLUSION}

This study has explained the central importance of incorporating comfort in driver's car seat design. As mentioned earlier, the main objectives of this study are twofold: First, to recommend a range of angles for driving posture comfort from measurement of samples and second, is to investigate the relationships between car drivers' anthropometric characteristics, comfortable postural angles and seat adjustment. This study has proposed a range of comfortable postural angles through comparison with the previous studies performed on Korean and Caucasian population. Results from the investigation on the relationships between car's driver anthropometric characteristics, comfortable postural angles and seat adjustment have produced several conclusions. The most significant finding that emerges from the relationship can be summarized as follows: (1) taller participants preferred a driving posture with their arms outstretched in order to achieve comfort; (2) participants with bigger body dimension have a tendency to sit further back from the steering wheels; (3) and smaller participants prefer to sit closer to the steering wheels with a slightly greater trunk thigh angle. These findings enhance our understanding of car drivers' perception of posture comfort. This study had produced results which corroborate the findings of a great deal of the previous study in this field. It is envisaged that the data and relationship discussed will assist the manufacturers in designing a drivers' car seat with ergonomic conscience. However these data must be interpreted with caution because the results are based on individual comfort perception. As a suggestion, more research on this topic needs to be undertaken before the relationship between the car seat design and drivers comfort can be clearly understood.

\section{ACKNOWLEDGMENT}

The researchers would like to acknowledge the financial contributions both from Ministry of Science, Technology and Innovation and Ministry of Higher Education for their research grants.

\section{REFERENCES}

Andreoni, G., G.C. Santambrogio, M. Rabuffetti and A. Pedotti, 2002. Method for the analysis of posture and interface pressure of car drivers. Applied Ergon., 33: 511-522. DOI: 10.1016/S00036870(02)00069-8

Costanzo, A., G. Graziani and G. Orsi, 1999. Driving ergonomy: New methodology for the assessment of stresses on upper limbs. Safe. Sci. Monitor.

Falou, W.E., J. Duchene, M. Grabisch, D. Hewson and Y. Langeron et al., 2003. Evaluation of driver discomfort during long-duration car driving. Applied Ergon., 34: 249-255. DOI: 10.1016/S0003-6870(03)00011-5

Grandjean, E., 1980. Sitting posture of car drivers form the point of view of ergonomics. Hum. Fact. Trans. Res., 2: 205-213.

Hermanns, I., N. Raffler, R.P. Ellegast, S. Fischer and B. Gores, 2008. Simultaneous field measuring method of vibration and body posture for assessment of seated occupational driving tasks. Applied Ergon., 38: 255-263. DOI: 10.1016/j.ergon.2007.05.007

Hinkle, D.E., W. Wiersma and S.G. Jurs, 1998. Applied Statistics for the Behavioral Sciences. Houghton Miffin Company, Boston, ISBN: 0618124055.

Hirao, K., S. Kitazaki and N. Yamazaki, 2006. Development of new driving posture focused on biomechanical loads. J. SAE Int., 100: 5-10.

JD Power and Associates, 2008. Perodua, Honda and Toyota Vehicle Models Each Rank Highest In Malaysia Initial Quality For a Second Consecutive Year. JD Power Asia Pacific Report, Malaysia Initial Quality Study SM (IQS). http://www.jdpower.com/corporate/news/releases/p ressrelease. aspx?ID=2008201

Kyung, G. and M.A. Nussbaum, 2008. Driver sitting comfort and discomfort (part II): Relationships with and prediction from interface pressure. Int. J. Ind. Ergon., 38: 526-538. DOI: 10.1016/j.ergon.2007.08.011 
Malaysian Standard, 2003. MS ISO 7250:2003 Basic human body measurements for technological design (ISO 7250: 1996, IDT). Department of Standards Malaysia, ICS: 13.180.

Massaccesi, M., A. Pagnotta, A. Socceti, M. Masali and C. Masiero et al., 2003. Investigation of workrelated disorders in truck drivers using RULA method. Applied Ergon., 34: 303-307. DOI: 10.1016/S0003-6870(03)00052-8

Na, S., S. Lim, H.S. Choi and K. Chung, 2005. Evaluation of driver's discomfort and postural change using dynamic body pressure distribution. Int. J. Ind. Ergon., 35: 1085-1096. DOI: 10.1016/j.ergon.2005.03.004

Park, S.J., C.B. Kim, C.J. Kim and J.W. Lee, 2000. Comfortable driving postures for Koreans. Int. J. Ind. Ergon., 26: 489-497. DOI: 10.1016/S01698141(00)00020-2

Porter, J.M. and D.E. Gyi, 1998. Exploring the optimum posture for driver comfort. Int. J. Vehicle Des., 19: 255-266.
Rebiffe, M.P., 1969. The driving seat: Its adaptation to functional and anthropometric requirements. Proceedings of the Symposium on Sitting Posture, (SSS'69) Taylor and Francis, London, pp: 132-147.

Reed, M.P., M.A. Manary, C.A.C. Flannagan and L.W. Schneider, 2000. Comparison of methods for predicting automobile driver posture. Proceeding of the Digital Human Modeling for Design and Engineering Conference and Exposition, June 2000, Dearborn, Michigan, pp: 1-1. http://papers.sae.org/2000-01-2180

Sun, S., Q. Wu, C. Chai and Y. Xiong, 2006. A driving posture prediction method based on driver comfort. Proceeding of the 7th International Conference on Computer-Aided Industrial Design and Conceptual Design, Nov. 17-19, IEEE Xplore Press, Hangzhou, $\quad$ pp: $1-5 . \quad$ DOI: 10.1109/CAIDCD.2006.329344 